\title{
Technological regimes in the Brazilian manufacturing industry: an empirical investigation
}

Vinícius Vieira*

Marcelo Resende**

Recebido: 15/10/2015 Versão Revisada (entregue): 02/03/2016 Aprovado: 25/04/2016

\section{ABSTRACT}

The paper aims to assess technological regimes in the context of the Brazilian manufacturing industry over the period 2000-2005. The industries were classified in terms of Schumpeter Mark I (SM-I) and Schumpeter Mark II (SM-II) technological regimes by using multivariate statistical methods based on variables approximating technological opportunity, appropriability, cumulativeness and knowledge base. The evidence indicated some salient classification contrasts with respect to the previous evidence obtained for developed countries. In particular, the pharmaceuticals and paper and cellulose sectors in the Brazilian case have some expected specificities. The contrasts between the SM-I and SM-II sectors for the totality of sectors indicated discernible differences in the case of two hypotheses: the share of small firms is higher in SM-I industries than in SM-II industries, and in SM-I industries the profit rates are lower than those in SM-II industries.

KEYWORDS | Technological Regimes; Manufacturing Industry.

JEL CODES | L60; O30

* BB DTVM, Banco do Brasil, Rio de Janeiro (RJ), Brasil. E-mail: vinicius.r.vieira@gmail.com

** Instituto de Economia. Universidade Federal do Rio de Janeiro (UFRJ), Rio de Janeiro (RJ), Brasil. E-mail: mresende@ie.ufrj.br 


\section{Regimes tecnológicos na indústria brasileira de transformação: uma investigação empírica}

\section{Resumo}

O artigo pretende avaliar os regimes tecnológicos no contexto da indústria brasileira de transformação, ao longo do período de 2000-2005. As indústrias foram classificadas em termos dos regimes tecnológicos Schumpeter Mark I (SM-I) e Schumpeter Mark II (SM-II), por meio de métodos de estatística multivariada baseados em variáveis que aproximam oportunidades tecnológicas, apropriabilidade, cumulatividade e base de conhecimento. A evidência indicou contrastes destacados na classificação relativamente às evidências anteriores para países desenvolvidos. Em particular, os setores farmacêutico e de papel e celulose possuem algumas especificidades no caso brasileiro. Os contrastes entre setores SM-I e SM-II para a totalidade de empresas indicaram diferenças significativas no caso de duas hipóteses: a participação de firmas pequenas é maior em indústrias SM-I do que naquelas SM-II; e as taxas de lucro são menores em indústrias SM-I do que nas SM-II.

PALAVRAS-CHAVE | Regimes Tecnológicos; Indústria de Transformação.

Códigos-JEL | L60; O30 


\section{Introduction}

The importance of abrupt economic changes following innovation have been noted since Schumpeter (1912, 1942), who contended that innovation is responsible for incessantly destroying the old and creating the new. The notion of creative destruction innovation encompasses radical innovations, which follow the precepts of creative destruction and dramatically alter existing structures, and incremental innovations, which follow an incremental process of creative accumulation.

A next logical step was to consider the extent to which sectoral characteristics would delineate innovation patterns. Pavitt (1984) considered inter-sectoral contrasts in innovation and advanced a taxonomy of innovation based on firm level aspects in which the author classified the sectors as supplier-dominated, production-intensive (scale-intensive and specialized suppliers) and science-based. These classifications differ with respect to sectoral differences between the sources of technology, user needs and the means of appropriation.

Nelson and Winter (1982) and Kamien and Schwartz (1982) also recognized the relevance of sector-specific characteristics in shaping innovations. Their studies laid the foundations for the notion of technological regimes and highlighted two salient innovative patterns: the first was characterized in terms of creative destruction, with an easy entry of new innovators, introducing new ideas, processes and products and having a disruptive effect on the competitive environment, thus delineating a widening pattern of the knowledge base. This pattern has been labeled Schumpeter Mark I (SM-I).

The second pattern was related to the notion of creative accumulation, in which the innovation process is conducted by large, established firms that have institutionalized the innovation process and that effectively create barriers to entry for new innovators. This pattern has been designated Schumpeter Mark II (SM-II), and it can be associated with a "deepening" pattern of innovation, in which a few firms that continuously accumulate technological and innovative capabilities over time dominate. In other words, a SM-II pattern innovative base is characterized by an accumulation strategy based on the existing technological premises and does not display continuous growth, as is found in a SM-I pattern.

The importance of knowledge for innovative activity has led authors to focus on the particularities of the knowledge base and how it is created. Recombinant knowledge recognizes that knowledge is heterogeneous and is composed of different subsets dispersed in a technological space and, therefore, its creation is the 
outcome of a search that takes different characteristics into account (KRAFFT et al., 2014a).

The characteristics of the knowledge base and their impact on technological regimes are another field of research, with authors such as Krafft et al. (2014b), whose study focuses on the technology lifecycle, which begins with the emergence of the knowledge discontinuity and proceeds by gradual transformations of the discontinuity into a routine economic system.

The concept of technological regimes articulates the technological opportunity, appropriability, cumulativeness and properties of the knowledge base that define SM-I and SM-II patterns of innovation. These concepts have motivated empirical studies, which were mostly applied to European countries and include Malerba and Orsenigo (1993, 1995, 1997), Mesa and Gayo (1999), Breschi et al. (2000) and Van Dijk (2000, 2002).

The majority of these studies emphasize the inter-sectoral heterogeneities associated with the structural and dynamic features in the populations of innovative firms. However, it is important to stress that the studies by Van Dijk $(2000,2002)$ further explore the contrasts between SM-I and SM-II industries in terms of statistical tests applied to specific hypotheses for firms in general.

The present paper aims to consider a similar analysis in the case of the Brazilian manufacturing industry, using as reference rich survey data that have become increasingly available. The study is motivated on different grounds:

- The existing literature has concentrated on developed countries, and it is important to investigate a large emerging economy such as Brazil, where the coexistence of traditional sectors and more dynamic and innovative sectors can be observed. Nevertheless, as suggested by Gonçalves and Simões (2005), Kannebley Jr. et al. (2005) and Zucoloto and Toneto Jr. (2005), it appears that the typical level of technological effort remains low.

- A large-scale empirical study of technological regimes that relies on different firm-level data sources to investigate sectoral patterns remains lacking in the context of developing economies, which have different patterns of industrialization and innovation. Furthermore, related evidence suggests that innovation is typically concentrated in the most developed countries. In this context, the present paper seeks to apply a widely accepted methodology to the Brazilian manufacturing industry to verify if the implied results are compelling and consistent. The underlying structural factors that define the two regimes warrant further investigation. Indeed, previous 
studies by Van Dijk $(2000,2002)$ rely on the prevailing classification used by Malerba and Orsenigo (1995) that referred to different countries. The consideration of tests comparing SM-I and SM-II industries that do not rely on classifications with regard to other countries is warranted, and the consideration of an emerging economy can address a gap in the literature. The adoption of an empirical methodology for classifying different sectors within the Brazilian manufacturing industry is the initial contribution of this paper. We face some limitations in terms of data availability, especially those related to patents, which leads us to adapt the previous data construction methodology, using surveys data that are proxies for technologies.

- We recognize that using data from innovation surveys instead of patent data imposes some limitations. However, the present study is one of the first attempts to apply an empirical methodology for classifying Brazilian manufacturing industries as SM-I or SM-II regimes. Based on Van Dijik $(2000,2002)$, we will conduct further tests of the hypotheses to gain more confidence in the adopted classification and to highlight the features of the industrial dynamics that may contrast between the two technological regimes.

The remainder of the paper is organized as follows. Section 2 briefly discusses the empirical classification of technological regimes and the empirical contrast between Schumpeter Mark I and Schumpeter Mark II regimes. Section 3 presents the background for classifying Brazilian sectors as SM-I and SM-II and describes the database, methodology and variables used in this paper. Section 4 shows the empirical results of this paper, presents the proposed empirical classification of Brazilian sectors and tests the empirical contrasts between the sectors classified into SM-I and SM-II. Section 5 presents some considerations on the differences between the classifications made for Brazil and others countries. Section 6 concludes.

\section{Technological regimes: empirical characterization}

A technological regime (NELSON; WINTER, 1982; WINTER, 1984) defines the particular knowledge environment in which a firm's problem-solving activities occur. In other words, a technological regime characterizes the regularities between firms and sectors that are generated by technological incentives.

After the identification of these regimes Winter (1984) analyzed the importance of new and established firms as sources of innovation. This study led to the 
definition of two distinct regimes: the entrepreneurial regime, which facilitates the entry of new innovative firms; and the routinized regime, which facilitates the innovation of incumbent firms.

These distinctions led Malerba and Orsenigo (1993, 1995, 1997), based on the developments of Schumpeter's conceptions of innovation, to create the Schumpeter Mark I (SM-I) and Schumpeter Mark II (SM-II) technological regimes, with the former being related to a pattern of creative destruction and the latter being related to creative accumulation. After this conceptual effort, the empirical verification of these categories became an appealing research topic.

A seminal empirical article was written by Malerba and Orsenigo (1997), who used patent application data from the European Patent Office (EPO) for six different developed countries (Germany, France, the UK, Italy, the USA and Japan) to reach the conclusion that innovative activity could be meaningfully separated into the two distinct technological regimes. The differences between the SM-I ("widening") and SM-II ("deepening") regimes, in accordance with these authors, were related to specific features of the industrial dynamics that reflect the form into which innovative activity evolves. The distinction between these regimes could be associated with the particular combination of four fundamental factors that define a technological regime NELSON; WINTER, 1982; WINTER, 1984; DOSI, 1982):

- Technological opportunity: this factor reflects how "easily" an innovation is achieved for a given amount that is invested in R\&D. A sector with a high level of technological opportunity provides incentives to innovative activities and indicates an economic environment that is not severely restricted, in the sense that innovations should emerge more frequently.

- Appropriability of innovations: this factor reflects the effectiveness of the instruments of intellectual property in protecting innovation.

- Cumulativeness of technical advances: this factor reflects the path dependence of innovation. In other words, knowledge and the current innovative activity influence future innovations.

- Properties of the knowledge base: these reflect the knowledge that underpins the innovative activity of firms. Breschi et al. (2000) focus on the generic (related to a very broad nature) vs. applied knowledge base (specialized and targeted to specific applications) dichotomy.

These four characteristics help define the SM-I regime, which has a high level of technological opportunity associated with low appropriability, cumulativeness 
conditions and the property of an applied knowledge base. The articulation of these conditions reflects intense industry dynamics, with a high rate of new innovators, low concentration and great instability in the innovator hierarchy.

By contrast, SM-II is characterized as a sector with a high level of technological opportunity, high appropriability and cumulativeness and a knowledge base closer to basic science. These conditions reflect sectors with a reduced level of entry of new innovators, a high concentration in innovative activities and an established hierarchy for the group of innovators.

The related empirical literature can be schematically summarized in two branches.

\subsection{Empirical classification of industries into SM-I and SM-II types}

Using the structural and dynamic factors that characterize the sectoral patterns of innovation, Breschi et al. (2000) propose a synthetic characterization of the technological regimes by means of a multivariate statistical method for their principal components (PC). The method attempts to describe variations in the observed data by considering linear combinations (the PCs) of the representative variables such that successively orthogonal PCs explain a decreasing proportion of the data variance. ${ }^{1}$ The procedure accounts for interpreting the signs of the coefficients of the dominant PC with respect to different variables (by inspecting the factor loadings) and classifying each industry into one of the two categories of technological regimes.

The first (dominant) PC - henceforth denoted SCHUMP - is obtained from the variables pertaining to technological entry and exit, the concentration of innovative activity and the stability in the ranking of innovators. The indicators used are as follows:

- ENTRY: the percentage share of patent applications by firms applying in a given technological class for the first time;

- STABILITY: the Spearman rank correlation coefficient between the hierarchies of firms filing patents in two different periods;

- C4: the concentration ratio of the top four patenting firms in a given technological class.

1 For an overview, see Manly (1994). 
The analysis relies on patent data from the EPO-CESPRI database, and an industry is classified as SM-I in the case of a negative and lower value for SCHUMP, whereas a positive and higher value favors the SM-II classification. To gain further confidence on the classification, Breschi et al. (2000) conduct an econometric analysis to investigate the relationship between the synthetic indicator SCHUMP and proxy variables for technological opportunity, appropriability, cumulativeness and the knowledge base. The results provide additional motivation for adopting a classification approach, as shown.

\subsection{Empirical contrasts between SM-I and SM-II}

The contrasts between the SM-I and SM-II regime rely on the differences in the appropriability, cumulativeness and knowledge conditions, and therefore, regimes are likely to differ in regard to their dynamics and structural properties. There are differences that make a SM-I regime more turbulent with respect to a large population of small firms but display low profit rates and low entry barriers. By contrast, a SM-II industry should have a more stable population, with a large population of large firms, high profit rates and high entry barriers. In this context, Van Dijk $(2000,2002)$ suggests the exploration of these contrasts between SM-I and SM-II regimes as the next natural step in research on technological regimes.

To that end, the author conducts tests for the differences in the means of selected hypotheses related to the distinctive characteristics of the technological regimes in the case of Dutch manufacturing firms. Moreover, the author's objective is to verify that sectors classified as a SM-I or SM-II regime present significant differences in their means. In other words, the author attempts to confirm that the division of Dutch industry in two broad groups, with exclusive and distinctive characteristics, is valid.

These statistical tests are conducted using a database of firms, allocated by a four-digit industry code, having more than 20 employees, and being active between 1978 and 1992. The classification of Dutch industries as SM-I or SM-II regimes is directly based on the taxonomy presented in Malerba and Orsenigo (1995) for Italy instead of developing a proper classification for the Dutch manufacturing industry.

The hypotheses tested are developed by the author based on the dynamics and structural characteristics of the SM-I and SM-II regimes and are summarized in Chart 1. 


\section{Chart 1}

Technological regimes: general contrasts - main hypotheses

\begin{tabular}{|l|l|}
\hline 1 & The share of small firms is higher in SM-I industries than in SM-II industries \\
\hline 2 & Concentration levels are lower in SM-I industries than in SM-II industries \\
\hline 3 & Entry barriers are lower in SM-I industries than in SM-II industries \\
\hline 4 & Capital intensity is lower in SM-I industries than in SM-II industries \\
\hline 5 & In SM-I industries, profit rates are lower than in SM-II industries \\
\hline 6 & $\begin{array}{l}\text { In SM-I industries, entrants are more productive than incumbents, whereas in SM-II } \\
\text { industries, incumbents are more productive than entrants }\end{array}$ \\
\hline 7 & $\begin{array}{l}\text { In SM-I industries, the amount of turnover due to entry and exit is higher than in SM-II } \\
\text { industries }\end{array}$ \\
\hline 8 & $\begin{array}{l}\text { The turbulence within the group of incumbent firms is higher in SM-I industries than in } \\
\text { SM-II industries }\end{array}$ \\
\hline 9 & $\begin{array}{l}\text { The contribution of the entry and exit process to productivity growth is higher in SM-I } \\
\text { industries than in SM-II industries, and vice versa for incumbents contributions }\end{array}$ \\
\hline
\end{tabular}

Source: Van Dijk (2002, p. 179-180)

In the present paper, we intend to consider both lines of research for the case of the Brazilian manufacturing industry by exploring multiple data sources that have not previously been explored in this context. Therefore, we intend to conduct a data-intensive study that can represent the first attempt at filling the gap in the literature for developing countries. The purpose of this paper is to build an empirical classification of Brazilian manufacturing industries as a SM-I or SM-II regime and, based on such classification, investigate the contrasts related to different aspects of the industry dynamics by means of tests for differences in means.

\section{Technological regimes in Brazil: data, methodology and variables}

\subsection{Data}

The main data source for the present study was provided by a comprehensive survey on technological innovation in the context of the Brazilian manufacturing industry (Pesquisa de Inovação Tecnológica - Pintec, Instituto Brasileiro de Geografia e Estatística - IBGE) conducted on a bi-annual basis with active firms with 10 or more employees whose main revenues were associated with extractive or manufacturing industries. The database was built from microdata for the years 2000, 2003 and 
2005. ${ }^{2}$ It is worth noting that the Pintec questionnaire conducted by IBGE closely follows the questionnaire administered by the Community Innovation Survey (CIS 1), which focuses on European countries. A complementary source of information was the annual industrial survey (Pesquisa Industrial Anual - PIA, Instituto Brasileiro de Geografia e Estatística - IBGE), which was combined with the Pintec database to construct a group of indicators related to industry characteristics.

Unlike the previous studies conducted by most authors who have analyzed the technological regimes in developed countries, this study, instead of measuring innovation by the number of patent applications, considers innovative activity indicators and sectoral indicators constructed based on the Pintec and from the matching of the PIA and Pintec data. The data description considers two steps of analysis involving the classification of sectors in terms of SM-I and SM-II technological regimes and the detection of contrasts between those regimes in terms of different structural and industry dynamics variables.

Tests that check for the differences between SM-I and SM-II are based on the universe of all firms whereas the first part of the study had relied on a sample of innovating firms.

To build those variables for the final sectoral analysis, we use the Relação Anual de Informações Sociais (RAIS, Ministry of Labor and Employment, Brazil), which is an annual census survey, over a 10-year period (1995-2005). Tests are conducted for the sectoral means of the variables noted above across the 10-year span.

Despite never having been used to categorize sectors as SM-I or SM-II, the Pintec and PIA data are commonly used to analyze innovation in the Brazilian manufacturing industry. Gonçalves et al. (2015) analyze the innovative patterns in the Brazilian agricultural machinery industry, classifying Brazilian companies according to their innovative capacity. Gonçalves and Yonamini (2013) use the Pintec database to classify Brazilian manufacturing industries into six different clusters, with each having its specific innovative characteristics.

\section{3,2 Methodology}

The first step of the classification of sectors into a SM-I or SM-II regime is to define which firms are considered innovators. To that end, we adopted a criterion in which innovators are firms that had positively responded to the question in the

2 The authors are grateful to the IBGE for access to the microdata of Pintec, which are subject to confidentiality and were provided solely for the purpose of this academic research. 
Pintec about whether they had implemented some process or product innovation or whether they had used some instrument of intellectual property (such as a patent, secrecy, a license or trademarks) during the survey period. ${ }^{3}$ This step contrasts the present paper and previous studies because in some of these studies the definition of innovating firms exclusively considers patent data. ${ }^{4}$

The process of classification starts based on the sub-group of innovative sectors classified at the 3-digit level (CNAE3). ${ }^{5}$ For this selected group, three sectoral indicators are built, using microdata: ENT, which captures the entry of new innovators; CONC, which measures the degree of concentration on innovative activity; and STAB, which measures the stability in innovative activity. These three variables are used as inputs in a principal component analysis (PCA) to create a fourth variable, designated SCHUMP, which is a linear combination of the ENT, CONC and STAB indicators.

The SCHUMP indicator is used to classify the industrial sectors as a SM-I or SM-II regime. When the factor score coefficient resulting from principal component analysis is negative, it indicates that the entry of innovators overrides the concentration and stability of innovators, which is consistent with a SM-I pattern. By contrast, when SCHUMP is positive, concentration and stability overcome the entry of new innovators, and therefore, the pattern is consistent with a SM-II pattern.

The process of classification is a distinctive characteristic of the current paper because we use an empirical framework to classify the sectors instead of assuming that the taxonomy applied to developed countries can be applied to an emerging country. Another development of the present paper is that all of the sectoral indicators were created based on microdata (firm-level data), which allow us to capture the real characteristics of the sector. In other words, we analyze data from all Brazilian firms, separating those that were innovative and active during the entire sample period and then create sectoral indicators.

3 Although the Pintec does not provide any information about the number or classification of a firm's patents, it does answer whether the firm used any type of intellectual property, such as patents.

4 The central data source of the study is provided by the Pintec-IBGE that typically captures firms that had experienced incremental innovations and is organized in terms of sectoral classifications from the CNAE. Alternatively, the use of patent data from the Brazilian institute of intellectual property (INPI) would face some obstacles: the non-trivial data extraction and difficulty in matching technological classes in terms of sectoral CNAE classifications; the number of patents, that would reflect more drastic innovations, is very low in Brazil as often more substantial innovations are carried out in the headquarters of multinational firms abroad; the patent process in Brazil is very slow in comparison with other countries and thus patent-based indicators also have shortcomings.

5 The sample of innovative sectors is composed of 69 sectors. 
To provide additional confidence in the classification system, we follow the lead of Breschi et al. (2000) and investigate the adherence of the sectors classified as a SM-I or SM-II regime by analyzing the variables related to technological opportunity (TECOP), appropriability (APROP), cumulativeness (CUMUL) and the knowledge base (either BASIC or APPL), as discussed above.

For this analysis, we considered the statistical technique of linear discriminant analysis (LDA). Given that our sample was divided into two groups (SM-I and SM-II), we could obtain discriminant functions in accordance with the criteria of maximizing the discrimination between groups and minimizing the heterogeneity within the groups. ${ }^{6}$ With these criteria as the objective, one can conceive a linear function of $\mathrm{p}$ variables that discriminate variables $\left(\mathrm{say}, \mathrm{X}_{1}, \ldots, \mathrm{X}_{\mathrm{p}}\right)$ that are likely to motivate the assignment of units into particular groups. In the present application, the aim is to classify industries in terms of the SM-I or SM-II technological regime. Specifically, for the $\mathrm{i}$-th unit, one would have the following:

$$
Z_{i}=b_{1}+b_{1} X_{1}+b_{2} X_{2}+\ldots+b_{p} X_{p}
$$

In our application, $Z_{\mathrm{i}}$ stands for the discriminant score of the $\mathrm{i}$-th 3-digit sector, $X_{\mathrm{ji}}$ refers to $\mathrm{i}$-th sector's value of the $\mathrm{j}$-th independent variable, and $b_{\mathrm{j}}$ denotes the discriminant coefficient for the $j$-th variable.

Discriminant functions are sensitive to the scale of the considered variables. Thus, we considered standardized variables, which were found by subtracting each value by the mean and then dividing by the standard deviation. The LDA approach can be useful as a type of validation of the adopted classification, and with 2 groups and 3 indicators, we had a single discriminant function. The discriminating effects of the aforementioned indicators on the innovation patterns (as summarized by the technological regimes) were considered in terms of the procedures outlined by Morrison (1969). In this sense, if $\left|b_{j ; S M-I}\right|>\left|b_{j ; S M-I I}\right|$ (where $b_{j}$ is the coefficient of the discriminant function associated with indicator $j$ ), then the indicator favored a SM-I regime. Conversely, if $\left|\mathrm{b}_{\mathrm{j} ; \mathrm{SM}-\mathrm{I}}\right|<\left|\mathrm{b}_{\mathrm{j} ; \mathrm{SM}-\mathrm{II}}\right|$, then the indicator favored a SM-II regime. After classifying sectors as SM-I or SM-II through PCA (which generated the SCHUMP variable) and verifying the classification by LDA, we need to verify whether there are significant differences between these two groups of sectors. To that end, we follow the steps developed by Van Dijik $(2000,2002)$ in analyzing the Dutch industry.

6 For useful introductions, see Klecka (1980), Manly (1994) and Lattin et al. (2003). 
In this sense, we explore the inter-industry contrasts by applying hypothesis tests to verify whether the means of selected variables show significant differences between the sectors classified as SM-I or SM-II. The hypothesis used follows those advanced by Van Dijik (2002), and to conduct the tests, we build nine variables, by using the RAIS database. Specifically: the share of small firms; the industrial concentration; the suboptimal scale; capital intensity; profit rates; labor productivity; the entry rate; the exit rate; and turbulence. It is worth noting that the RAIS is a survey that collects data for all Brazilian (formal) firms, and that does not distinguish between innovators and non-innovators.

The referenced empirical approach use tests for the difference in means in the form ${ }^{7}$ of:

$$
t=\frac{\bar{x}-\bar{y}}{\sqrt{\frac{\left(n_{x}-1\right) s_{x}^{2}+\left(n_{y}-1\right) s_{y}^{2}}{n_{x}+n_{y}-2}} \sqrt{\frac{1}{n_{x}}+\frac{1}{n_{y}}}}
$$

The null hypothesis of the test is the equality of means across different groups, and the statistic is distributed as a Student $t$ with $\left(n_{x}+n_{y}-2\right)$ degrees of freedom. However, this version for unequal sample sizes assumes equal variances. If this requirement is not tenable, then we must rely on test expression (2), known as Welch's $\mathrm{t}$ test:

$$
t=\frac{\bar{x}-\bar{y}}{\sqrt{\frac{s_{x}^{2}}{n_{x}}+\frac{s_{y}^{2}}{n_{y}}}} \sim t(v)
$$

Under the null hypothesis, the relevant degrees of freedom are obtained in accordance with the Satterthwaite formula ${ }^{8}$. Therefore, it is important to assess the constancy of variances prior to the application of the test for the differences in means to determine the appropriate version. To that end, we consider Lavene's test, as properly outlined by Forsythe and Brown (1974). All of the tests are conducted with Stata 11.0.

\footnotetext{
7 For an introduction to these tests, see Dixon and Massey (1983).

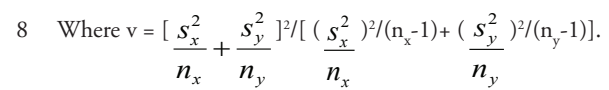




\subsection{Variables}

To classify industries as SM-I and SM-II, we build three variables (ENT, CONC and STAB). These variables are built as follows:

- ENT: this variable aims to capture the entry of new innovators and is calculated by using data from the Pintec surveys for 2000, 2003 and 2005, with a 3-digit sector code. It represents the share of new innovators in the innovator population. The identification of new innovators is performed by counting the number of firms for each sector that first appeared as innovators in $2005^{\circ}$ and then dividing this number by the number of innovators.

- CONC: this variable measures the level of concentration in innovative activity. The concentration is measured at a sectoral level, using firm-level data from the 2005 Pintec. This indicator is calculated by retrieving from the Pintec the share of the revenue attributed to innovative activities and then matching this amount with the data from the 2005 PIA on the total revenue for the same firms. The combination of these two variables allows us to create "innovation revenue" with firm-level data. The indicator for concentration is implemented in terms of a Herfindahl index, defined as $\mathrm{H}=\Sigma_{\mathrm{i}} \mathrm{s}_{\mathrm{i}}{ }^{2}$, where $s_{\mathrm{i}}$ is the share of the firm innovation revenue in the total innovation revenue of the sector.

- STAB: this variable measures stability in innovation activity. The hierarchical stability of innovators aims to approximate the degree of technological dynamism in the sector. To build this indicator, we first identify the innovating firms in 2000 (based on the Pintec), and then, we determine the innovation revenue based on the procedure described in the previous item for 2000 and $2005,{ }^{10}$ calculating the Spearman rank correlation for each sector. Given the small number of firms in some sectors, we consider only those for which the correlation coefficient was significant. The consequence is a reduction in the number of sectors in our analyses because, after starting from an initial sample of 112 sectors at the 3-digit level

9 We consider new innovators to be firms whose first innovation was made only in 2005. For example, if a firm made an innovation in 2003 and in 2005, we do not consider this firm to be a new innovator.

10 In cases in which the firm innovated only in one of these years, we assume that the innovation revenue is zero for the year that the firm did not make any innovation. 
(comprising extractive and manufacturing industries), we end up with a final sample composed of 69 sectors.

These three variables were used as inputs in a principal components analysis (PCA) in which the first principal component captured $53.3 \%$ of the sample variance, thus allowing us to retain only the first component, which we designated SCHUMP and use to classify the sectors as SM-I or SM-II. In other words, SCHUMP is a linear combination of the ENT, CONC and STAB variables and is defined as follows:. The coefficients associated with these variables are built from the PCA, and the summary statistics and the results for the indicators are presented in Appendix I and Appendix II.

This variable is meant to be an indicator of the technological regimes followed by the sector. A negative variable indicates that the entry of innovators overrides the concentration and stability of innovators, which is consistent with a SM-I pattern. By contrast, when SCHUMP is positive, concentration and stability overcome the entry of new innovators, and therefore, the pattern is consistent with SM-II.

For the discriminant analysis of Brazilian sectors classified as SM-I or SM-II, we consider the role of the variables related to technological opportunity (TECOP), appropriability (APROP), cumulativeness (CUMUL) and the knowledge base (either BASIC or APPL), as discussed above. The following variables are constructed based on the Pintec survey:

- TECOP: this variable is the indicator for technological opportunity and aims to measure how easily innovations are likely to emerge in a given sector. The indicator is built by adding firms' responses to a question related to the importance of available external sources of innovation for the development of innovation. This variable aims to capture how easy it is for a firm to use the information available in the environment and achieve an innovation. The patterns of technological opportunity, as described by Klevorick et al. (1995), can distinguish between two groups: the first is rich in technological opportunities, having strong linkages with different sciences and external sources of knowledge, whereas the second has opportunities that are related to knowledge of one (vs. all) science and weaker linkages with external sources of knowledge. A larger value indicates greater technological opportunities, given that it reflects the perception of "how easy" it is for a firm to achieve innovation. 
- APROP: this variable is the indicator of the appropriability of the innovative activity and is meant to identify the degree of protection conferred by intellectual property rights. This indicator is obtained by adding innovating firms' responses to questions related to the importance of patents and other intellectual property mechanisms. The smaller the value is, the greater the appropriability conditions.

- CUMUL: this indicator attempts to capture the degree of dependence between innovation and past technological knowledge. The indicator is constructed by adding firms' responses with respect to the prevailing constancy with which they undertake research and development. The idea of this indicator is based on the notion that a firm's continuous flow of innovation could be caused by a path dependence in innovative activity. A larger value denotes a higher level of cumulativeness.

- KBASE: this indicator refers to the knowledge base, and its objective is to identify the extent to which technological knowledge has a more generic or more applied dimension. Following the lead of Breschi et al. (2000), we focus on the generic versus specific dimension of knowledge. For innovating firms, we consider the share of employees who possess an educational background related to generic and applied knowledge. For this category, we construct the following two indicators:

- BASIC: this indicator attempts to identify how generic (basic) the knowledge base is. It is obtained by calculating the share of employees with a professional background in basic/generic sciences (chemistry, physics, biology, and mathematics) relative to the total number of employees in the firm. Thus, the larger the value of the basic science indicator is, more generic the technological knowledge is, which implies a low degree of concentration in innovative activity, with a large number of innovators.

- APPL: this indicator attempts to identify how applied the knowledge base is. It is obtained by calculating the share of employees with a professional background in applied sciences (e.g., engineers, physicians, architects). Thus, a larger basic science indicator value indicates that the technological knowledge is more applied, which can cause a high degree of concentration in innovative activity and a high stability (low turbulence) between innovators.

To test whether there are significant differences between SM-I and SM-II sectors, hypothesis testing was conducted. Nine variables were built, using the 
PIA and RAIS databases. The different indicators were constructed at the sectoral level in terms of a consistent CNAE classification. As for the aggregation level, it is important to stress that initial classification in terms of SM-I and SM-II regimes was based on 3-digit aggregation that enabled a minimum acceptable number of firms in each sector. However, in the second stage of the analysis, pertaining to the comparison of sectors under the referred technological regimes, was available at the 4-digits level. Thus, in order to implement the hypotheses tests, all 4-digits sectors that were within a same 3-digit sector were classified in terms of the technological regime attributed to that more aggregated sector in the previous classification stage of the analysis. The sectoral indicators for assessing contrasts between SM-I and SM-II regimes are as follows:

- Share of small firms: this variable is measured in terms of the number of employees. We consider small firms to be those with more than 5 and less than 100 employees.

- Industrial concentration: this variable is a Herfindahl index at the 4-digit level, calculated with the revenues of firms, obtained through a specially requested tabulation from the PIA-IBGE.

- Suboptimal scale: this variable is measured as the average proportion of employment in firms below the minimum efficient scale (MES) during the period 1995-2005. The MES is calculated by using the approach advanced by Sutton (1991), where the median of the number of employees per sector is calculated. Taking the MES proxy as reference, we consider the total number of employees in a given sector who were in firms that operate below the MES and thus generate the related proportion relative to the total number of employees in the sector. This calculation is performed for all years between 1995 and 2005, and the variable used in the tests is the sectoral average proportion of firms below the MES in each period.

- Capital intensity: this variable is measured by the capital stock divided by revenue. The capital stock is obtained through the perpetual inventory method by relying on the different years of the PIA survey where the sectoral revenue data are readily available ${ }^{11}$. The variable used in the test is the capital intensity average during the period 1996-2005. It is worth noting that, due to data limitations, we were only able to build this variable at the 3-digit level.

11 Additional details on the construction of the capital stock data are discussed in Appendix III. 
- Profit rate: this variable is calculated by dividing the gross value of production (discounting operating expenses) by total revenue. The variable used in the test is the mean profit rate between 1995 and 2005. This variable is built at the 4-digit level.

- Labor productivity: this variable is calculated as the gross production value divided by the total number of employees, as obtained from the PIA at the 4-digit level.

- Entry rate: this variable is measured as the number of new firms relative to the previous year. The entry is calculated by comparing the number of firms that declared having no employees in one year and having at least one employee in the following year. The variable considers the average of the share of new firms in the total number of firms in a sector between 1995 and 2005. This variable is calculated at the 4-digit level based on data from the RAIS ${ }^{12}$.

- Exit rate: this variable is measured as an analogous calculation for entry firms.

- Turbulence: this variable is calculated as the mean annual changes in the proportion of employees (relative to total employment in the sector) for firms that were active throughout the sample period (1995-2005). The calculation of this variable is performed by verifying the firms that were active in 1995 and remained active in 2005.

\section{Technological regimes in Brazil: empirical results}

\subsection{Empirical classification of Brazilian sectors}

After obtaining the SCHUMP variable for all Brazilian sectors, we classified 14 as SM-I and 55 as SM-II. Descriptive statistics were used to verify whether the sectors were properly classified. Accordingly, through this methodology, we found evidence favoring the classifications performed because the mean and median of entry in SM-I were higher than in SM-II and the concentration and stability were higher in SM-II than in SM-I. Although this classification is in line with the theoretical assumptions, we opted to conduct a discriminant analysis as a method of checking whether there were classification mistakes not captured by the descriptive analysis.

12 The identification of entering and exiting firms required identification codes for comparison across successive years; once again, we had special access to the restricted microdata. 
An initial analysis leads us to the following discriminant function:

$$
Z=-3.314+2.141 \text { (Oport) }-0.735(\text { Aprop })+0.037(\text { Cumul })+0.348(\text { Bass })+0.794(\text { Aplic })
$$

Table 1 reveals some inconsistencies with the theory because the discriminant coefficient associated with CUMUL in the SM-I indicates that a higher value for that indicator will favor the probability of classification as SM-I when the opposite result is expected. Therefore, to acquire more confidence in the LDA approach, we calculate discriminating scores $\left(Z_{i}\right)$ for each of the 3-digit sectors, and motivated by Morrison (1969), we adopt a classification rule such that $Z_{S M-I}>Z_{S M-I I}$, which suggests classification as SM-I. In other words, when the discriminant scores associated with SM-I are larger than those associated with SM-II, the sector should be classified as SM-I.

TABLE 1

Discriminant coefficients - initial analysis

\begin{tabular}{l|c|c|c}
\hline \multicolumn{1}{c|}{ Indicators } & $\mathbf{b}_{\text {j;SM-I }}$ & $\mathbf{b}_{\text {j;SM-II }}$ & $\mathbf{b}_{\text {j;SM-I }}-\mathbf{b}_{\text {j;SM-II }}$ \\
\hline TECOP & 4.140 & 1.999 & 2.141 \\
APROP & -1.153 & -0.418 & -0.735 \\
CUMUL & 2.316 & 2.279 & 0.037 \\
BASIC & -0.148 & -0.496 & 0.348 \\
APPL & 0.760 & -0.034 & 0.794 \\
CONSTANT & -5.857 & -2.543 & -3.314 \\
\hline
\end{tabular}

Source: Elaborated by the the authors based on data released by IBGE

Indeed, misclassifications appeared to be non-negligible. It was possible to identify 3 of the 14 SM-I sectors that were misclassified. Similarly, 7 of the 55 SM-II sectors appeared to involve misclassifications. After adjusting the classifications as outlined above, we obtained the discriminant function, and the related results are presented in Table 2:

$Z=-10,983+6,526($ Oport $)-1,413($ Aprop $)-1,070($ Cumul $)+3,024$ (Bass) +2.390 (Aplic) 
The results show consistency with the expected economic fundamentals discussed by Breschi et al. (2000). In particular, sectors with greater technological opportunities are classified as SM-I, and sectors with greater appropriability and cumulativeness are classified as SM-II. Thus, the results found after classifying the sectors as SM-I or SM-II suggest a plausible classification. However, given that we construct the variables differently from those used by other authors, a final verification of the separation power associated with the discriminant function is warranted.

TABLE 2

Discriminant coefficients - adjusted sectors

\begin{tabular}{|c|c|c|c|}
\hline Variables & $\mathbf{b}_{\mathrm{j} ; \mathrm{SM}-\mathrm{I}}$ & $\mathbf{b}_{\mathrm{j} ; \mathrm{SM}-\mathrm{II}}$ & $\mathbf{b}_{\mathrm{j} ; \mathrm{SM}-\mathrm{I}}-\mathbf{b}_{\mathrm{j} ; \mathrm{SM}-\mathrm{II}}$ \\
\hline TECOP & 9.618 & 3.092 & 6.526 \\
\hline APROP & -2.036 & -0.623 & -1.413 \\
\hline CUMUL & 0.984 & 2.055 & -1.070 \\
\hline BASIC & 3.109 & 0.085 & 3.024 \\
\hline APPL & 2.756 & 0.366 & 2.390 \\
\hline CONSTANT & -13.788 & -2.804 & -10.983 \\
\hline
\end{tabular}

Source: Elaborated by the the authors based on data released by IBGE

This analysis allows us to verify whether sectors have different statistical properties.

We calculate the eigenvalue and the canonical correlation, which is a synthetic measure of the association between groups of variables, considering linear combinations of indicators in each group to maximize the related correlation. The evidence is summarized below.

TABLE 3

Canonical correlation and eigenvalues associated to the discriminant function

\begin{tabular}{c|c|c|c|c}
\hline $\begin{array}{c}\text { Canonical } \\
\text { correlation }\end{array}$ & Eigenvalue & Likelihood ratio & $\begin{array}{c}\text { F (5,63) } \\
\text { statistic }\end{array}$ & p-value \\
\hline 0.847 & 2.541 & 0.282 & 32.02 & 0.000 \\
\hline
\end{tabular}

Source: Elaborated by the the authors based on data released by IBGE

Note: The null hypothesis assumes that the canonical correlation is zero. 
The SM-I and SM-II patterns were well discriminated by the corresponding function, given the observed high eigenvalues, the canonical correlation and the high significance indicated by the obtained p-value. Moreover, the Mahalanobis distance had a value of 12.238 with a corresponding statistic of $F(5,63)=30.620$ [p-value: 0.000], which therefore provided evidence of a significant distance between the mean vectors of the SM-I and SM-II patterns.

Finally, to further confirm such differences in the means, we calculated the Wilks' lambda test, which yielded a statistic of 0.2824 , with a p-value of 0.000 . This result shows that the previous evidence based on the different tests favored the rejection of the null hypothesis and thus delineated the significant mean discrepancies between the SM-I and SM-II sectors.

\subsection{Empirical classification of Brazilian sectors}

Van Dijk (2000, 2002) explores inter-industry contrasts for industrial sectors classified in terms of technological regimes by applying hypothesis tests to verify whether the mean of the selected variables show significant differences between the sectors classified as SM-I or SM-II. This analysis takes the totality of the population as reference and not only a sample of innovating firms. The related hypotheses are summarized in Chart 1 and are considered in the next sub-section.

The one-tailed tests for the difference in means related to the different hypotheses listed in Chart 1 are presented in Table 4. Due to data availability restrictions, we are not able to test hypotheses 6 and 9 noted above.

In the previous analogous tests conducted by $\operatorname{Van} \operatorname{Dijk}(2000,2002)$ for industry in the Netherlands, there was a strong support for the various hypotheses presented in Chart 1 and, consequently, for the representativeness of the SM-I and SM-II classifications of industrial sectors. However, we must be cautious, given that the classifications used in these studies were based on evidence obtained by Malerba et al. (1995) for a different country, which could have introduced some bias into their analysis. Thus, the tests presented in this sub-section attempt to partially fill a gap in the literature by recognizing that there are specificities in emerging economies and try to contribute to the empirical literature by attempting to implement a proper methodology to classify the industrial sectors in accordance with the characteristics of the Brazilian manufacturing industry. 
TABLE 4

One-tailed tests for difference in means

\begin{tabular}{|c|c|c|c|c|c|c|}
\hline & Hypotheses & $\begin{array}{c}\text { Test } \\
\text { statistic }\end{array}$ & $\begin{array}{c}\text { Mean } \\
\text { (std. error) } \\
\text { SM-I } \\
\end{array}$ & $\begin{array}{c}\text { Mean } \\
\text { (std. error) } \\
\text { SM-II } \\
\end{array}$ & $\begin{array}{c}\text { p-value } \\
(\text { diff. }>0)\end{array}$ & $\begin{array}{c}\text { p-value } \\
(\text { diff. }<0)\end{array}$ \\
\hline 1 & $\begin{array}{l}\text { The share of small } \\
\text { firms is higher in } \\
\text { SM-I industries } \\
\text { than in SM-II } \\
\text { industries }\end{array}$ & 3,235 & $\begin{array}{c}0.576 \\
(0.015)\end{array}$ & $\begin{array}{c}0.502 \\
(0,017)\end{array}$ & 0.001 & - \\
\hline 2 & $\begin{array}{l}\text { Concentration } \\
\text { levels are lower } \\
\text { SM-I industries } \\
\text { than in SM-II } \\
\text { industries }\end{array}$ & $-1.493\left({ }^{*}\right)$ & $\begin{array}{c}0.169 \\
(0.181)\end{array}$ & $\begin{array}{c}0.208 \\
(0.174)\end{array}$ & - & 0.069 \\
\hline 3 & $\begin{array}{l}\text { Entry barriers are } \\
\text { lower in SM-I } \\
\text { industries than in } \\
\text { SM-II industries }\end{array}$ & $-1.125\left(^{*}\right)$ & $\begin{array}{c}0.086 \\
(0.004)\end{array}$ & $\begin{array}{c}0.094 \\
(0.006)\end{array}$ & 0.869 & - \\
\hline 4 & $\begin{array}{l}\text { Capital intensity } \\
\text { is lower in SM-I } \\
\text { industries than in } \\
\text { SM-II industries }\end{array}$ & $-1.078\left(^{*}\right)$ & $\begin{array}{c}0.156 \\
(0.035)\end{array}$ & $\begin{array}{c}0,218 \\
(0.178)\end{array}$ & - & 0.144 \\
\hline 5 & $\begin{array}{l}\text { In SM-I industries, } \\
\text { profit rates are } \\
\text { lower than in SM- } \\
\text { II industries }\end{array}$ & -2.776 & $\begin{array}{c}0.352 \\
(0.012)\end{array}$ & $\begin{array}{c}0.423 \\
(0.250)\end{array}$ & - & 0.003 \\
\hline \multirow{2}{*}{7} & $\begin{array}{l}\text { Entry rate is larger } \\
\text { in SM-I industries } \\
\text { than in SM-II } \\
\text { industries }\end{array}$ & $0.232\left(^{*}\right)$ & $\begin{array}{c}0.051 \\
(0 ; 002)\end{array}$ & $\begin{array}{c}0.050 \\
(0.002)\end{array}$ & 0.408 & - \\
\hline & $\begin{array}{l}\text { Exit rate is larger } \\
\text { in SM-I industries } \\
\text { than in SM-II } \\
\text { industries }\end{array}$ & -1.102 & $\begin{array}{c}0.054 \\
(0.002)\end{array}$ & $\begin{array}{c}0.571 \\
(0.003)\end{array}$ & 0.864 & - \\
\hline 8 & $\begin{array}{l}\text { The turbulence } \\
\text { within the group } \\
\text { of incumbent firms } \\
\text { is higher in SM-I } \\
\text { industries than in } \\
\text { SM-II industries }\end{array}$ & $0.258\left(^{*}\right)$ & $\begin{array}{c}0.147 \\
(0.007)\end{array}$ & $\begin{array}{c}0.145 \\
(0.006)\end{array}$ & 0.398 & - \\
\hline
\end{tabular}

Source: Elaborated by the the authors based on data released by IBGE and RAIS-MTE

$\left({ }^{*}\right)$ Indicates acceptance of the equality of variances in accordance to Lavene's test considered at the $5 \%$ significance level. In the cases of non-rejection of the hypothesis of equal variances, one considered the $t$ test for differences in means in the version indicated in expression (2) whereas in other cases in the version from expression (3). 
The test results show that the contrasts between SM-I and SM-II are not overly sharp. Indeed, significant differences can be observed for only two hypotheses. The share of small firms is higher in SM-I industries than in SM-II industries (hyp. 1) and profit rates are lower in SM-I industries than in SM-II industries (hyp. 5).

The somewhat weak results pertaining to the differences between the SM-I and SM-II sectors can be analyzed from two perspectives. In terms of the empirical data, we work with constructed indicators that were based on data obtained from the PIA, Pintec and RAIS instead of patent data, as in previous works. Although all of the indicators that were constructed attempt to capture the same underlying meaning of those built from patent data in other studies, one cannot rule out the possibility of noise in our data. Thus, although the hypothesis testing is suggestive, some caution must be exercised with regard to sharp conclusions and the exploratory character of the study must be acknowledged.

Another point that could have had some impact on the test results is related to the specificities of the Brazilian sectors, which could lead to sectoral patterns of innovation that do not reflect the same standards as those in developed countries. Support for this view can be found in Guidolin (2007), who sought to classify the Brazilian manufacturing industry into technological regimes as proposed by Marsali (2002). This study showed that the technological regimes observed in the Brazilian manufacturing industry are different from those observed in developed countries mainly because of the intrinsic characteristics of the Brazilian innovative process, which differ significantly from those of developed countries.

Silva (2013) built a taxonomy for the Brazilian manufacturing industry based on the innovative efforts of companies, grouping sectors with the same characteristics. Moreover, similarly to the present study, it was possible to distinguish sectors with the same characteristics and build four groups of sectors, but without significant differences between them, with sectors having a low level of innovative intensity being dominant in each group.

These results demonstrate that the significant differences between analyses developed for the Brazilian manufacturing industry and those built for developed countries could be motivated by the differences in the intrinsic characteristics of each country and its industrialization process. Thus, the different results of the hypothesis tests do not necessarily indicate a non-significant differentiation between the SM-I and SM-II technological regimes but rather could potentially indicate the specificities of Brazilian sectors and innovation patterns that may warrant the consideration of additional hypotheses in the testing of contrasts between the SM-I and SM-II regimes. 


\subsection{Technological regimes in Brazil: considerations on the differences in classification}

Despite all of the developments by Breschi et al. (2000) for Italy, Germany and the United Kingdom and by Mesa and Gayo (1999) for Spain, ${ }^{13}$ it is possible to observe that sectors related to textiles, electrical equipment, machines and equipment generally appear to follow a SM-I pattern. By contrast, sectors related to chemicals, pharmaceuticals, oil and gas, and vehicle manufacturing appear to conform to a SM-II pattern. These types of patterns can easily be explained by the differences in the industrialization process.

In the Brazilian case, similar patterns emerged in these sectors; however, a contrast was provided in the case of pharmaceuticals, which was classified as SM-I. The difference in the classification was expected because the pharmaceutical industry in Brazil has much lower investments in R\&D than do the pharmaceutical industries of developed countries. The Brazilian pharmaceutical industry is one of the leaders in generic drug manufacturing, which is technology-intensive; however, this segment is less R\&D-intensive, and the fact that we built the innovation indicators based on the resources directed to $R \& D$ could be the cause of this difference in results. In other words, if we were able to work with patent data, then this result could have been different because we potentially could have captured the technology dimension in a more accurate form.

Another sector that presents a distinctive characteristic was the pulp and paper sector, which is typically classified as SM-I in developed economies and as SM-II in the Brazilian case. This difference may be explained by the peculiar dynamics of the Brazilian pulp and paper sector, given that Brazil is one of the leaders in innovation in this sector, is intensive in scale and has a high level of cooperation, as shown by Mayumi et al. (2008).

Dores et al. (2007) show that Brazilian pulp and paper companies are characterized as being integrated from the beginning of the chain, being highly capital-intensive, and having high efficiency and minimal scales. Moreover, this sector displays cyclical pricing behavior and is highly concentrated, with the seven largest companies, in 2005 , accounting for over $90 \%$ of production. Such contrasts suggest that national differences influence the sector's innovative characteristics and, consequently, the classification of the sector. These results suggest that the inherent

13 These authors focus on patent indicators to define innovating firms and thus work with technological classes. Therefore, a straightforward comparison with the Brazilian case is not readily available, but some salient results can be noted. 
conditions of each country have an impact on innovative activity that, consequently, is reflected in the classification of technological regimes.

Indeed, different countries exhibit differences in the effectiveness of their intellectual property mechanisms, the size of the domestic market, the competition faced by firms, and the forms of organizational and managerial settings. All of these differences impact the sectoral classification. Once we assume that conditions vary across countries, the classification of the sector should vary between the countries as well.

It is worth noting that the discussion on observed differences can, in principle, be enriched by the conceptual framework of National Innovation Systems (see e.g. NELSON, 1993; PATTEL; PAVITT, 1994) ALBUQUERQUE, 1997). This theory typifies three types of categories: innovation systems that enable countries to maintain their leadership in the international technological process (these systems comprise developed countries at the technological frontier); innovation systems that aim at disseminating innovation (these systems comprise countries with high technological dynamism, which are able to absorb technological advances generated in the most advanced centers); incomplete systems of innovation, which are the case of countries whose systems of science and technology do not evolved to a national system of innovation.

Brazil is included in this third group, what indicates that it is relatively inefficient, with lower investments in R\&D and lower intellectual production, as compared with developed countries. These differences can help to understand why the results of our test to Brazilian sectors are so different from those conducted for developed countries and may reflect institutional particularities. However, as the objective of this paper is not to investigate the innovation system in Brazil, additional studies need to be undertaken in order to verify whether specificities in the innovation systems can explain the sectoral contrasts that are identified in the present study.

\section{Final comments}

This paper aimed to assess technological regimes in the context of the Brazilian manufacturing industry. The classification procedure for identifying SM-I and SM-II technological regimes followed the lead of Breschi et al. (2000), with different criteria for defining innovating firms. In the majority of cases, the obtained results were somewhat intuitive, and some salient classification discrepancies with developed countries emerged. The validation of the classification by means of discriminant analysis provided additional confidence in the results obtained. 
This paper used empirical and statistical methods to find a good classification for the Brazilian manufacturing industry in accordance with a pre-established technological regime characterization. Therefore, the classification methodology created in this paper was our major contribution. However, given that we faced data availability restrictions, especially with regard to technologies (patents), additional studies must be conducted to verify whether the data built in this study were able to capture the essence of technologies.

Another point that warrants further research is the use of sectoral data to analyze technological regimes. Although the use of these data to study innovation in the Brazilian manufacturing industry and classify it into different clusters is widespread, additional studies must be conducted to alleviate any doubts about the classifications.

Finally, a set of hypotheses advanced by Van Dijk $(2000,2002)$ was proposed to contrast the SM-I and SM-II sectors against the totality of firms. The results obtained were weaker than those obtained for the industrial sectors in the Netherlands. However, it is important to bear in mind that the sectoral classification used in those studies relied on evidence from another country. In the present study, which is not subject to this potential shortcoming, the evidence seems to indicate less clear-cut contrasts between sectors under the two technological regimes. However, these weaker results do not invalidate the classification process, and they only show that there are differences between the characteristics of industrial sectors in a developed country and those in its emerging peers. Once again, these weak results may partially be due to the differences in the database used in this study as compared with other data sources used to study different countries.

This study was the first attempt to perform an empirical classification of the Brazilian manufacturing industry in terms of SM-I and SM-II technological regimes. Future research could start from the classification performed in the present study and attempt to improve the hypotheses considered in the tests. Other avenue for research could explore the causes of the differences between the results found for a developed country and those found for an emerging country, such as Brazil.

\section{References}

ALBUQUERQUE, E. M. Sistema nacional de inovação no Brasil: uma análise introdutória a partir de dados disponíveis sobre a ciência e tecnologia. Revista de Economia Política, $\mathrm{n}$. 16, n. 3, p. 56-72, 1996. 
ALVES, P.; SILVA, A. M. Estimativa do estoque de capital das empresas industriais brasileiras. Brasília: IPEA, 2008 (Texto para discussão, n. 1325).

BRASIL. Ministério do Trabalho e Emprego. Relação Anual de Informações Sociais, Brasília: Ministério do Trabalho e Emprego.

BRESCHI, S.; MALERBA, F., ORSENIGO, L. Technological regimes and schumpeterian patterns of innovation. Economic Journal, v. 110, issue 463, p. 388-410, April 2000.

BROWN, M. B. Robust tests for the equality of variances. Journal of the American Statistical Association, v. 69, issue 364-367, 1974.

CASTELLACCI, F. Technological paradigms, regimes and trajectories: manufacturing and service industries in a new taxonomy of sectoral patterns of innovation. Research Policy, v. 37, n. 6/7, p. 978-994, 2008.

DIXON, W. J.; MASSEY, F. J. (Introduction to statistical analysis. 4. ed. Boston: McGraw Hill, 1983. 426-441.

DORES, A. M. B.; CHAGAS, F. B.; GRION DE MATOS, R. L.; GONÇALVES, R. M. (Panorama setorial: setor florestal, celulose e papel. Papel e celulose. Rio de Janeiro: Banco Nacional de Desenvolvimento (BNDES), 2007.

DOSI, G. Technological paradigms and technological trajectories: a suggested interpretation of the determinant and direction of technological change. Research Policy, v. 11, issue 3, p. 147-162, 1982.

FERREIRA, P. C.; GUILLÉN, O. T. C. Estrutura competitiva, produtividade industrial e liberalização comercial no Brasil. Revista Brasileira de Economia, v. 58, n. 4, p. 507-532, 2004.

FORSYTHE, A. B.; BROWN, M. B. Robust test for the equality of variances. Journal of the American Statistical Association, v. 69, issue 346, p. 364-367, 1974.

GONÇALVES, E.; SIMÕES, R. Padrões de esforço tecnológico da indústria brasileira: uma análise setorial a partir de técnicas multivariadas. Revista de Economia, v. 6, n. 2, p. 391-433, 2005.

GONÇALVES, E.; LEMOS, M. B.; FAJARDO, B. A. G. Padrōes de Inovação da Indústria de Bens de Capital Agrícola no Brasil. Pesquisa \& Debate, v. 26, n. 1(47), p. 216-235, 2015.

GONÇALVES, F. O.; YONAMINI, F. M. Em busca de uma nova taxonomia de regimes tecnológicos para a indústria de transformação brasileira. EconomiA, v. 14, n. 1A, p. 145$158,2013$.

GUIDOLIN, S. M. Inovação, estrutura e dinâmica industrial: um mapeamento empírico dos regimes tecnológicos da indústria brasileira. 2007. 129 f. Dissertação (Mestrado em Economia) - Universidade Federal do Rio Grande do Sul, Porto Alegre, 2007. 
IBGE - Instituto Brasileiro de Geografia e Estatística. Classificação Anual de Atividades Econômicas-CNAE. Rio de Janeiro: IBGE, 2002.

KAMIEN, M. I.; SCHWARTZ, N. L. Market Structure and Innovation. New York:Cambridge University Press, 1982.

KANNEBLEY JR., S.; PORTO, G. S.; PAZELLO, E. T. Characteristics of Brazilian innovative firms: an empirical analysis based on Pintec-industrial research on technological innovation. Research Policy, v. 34, issue 6, p. 872-893, 2005.

KLEVORICK, A. K.; LEVIN, R. C.; NELSON R. R.; WINTER, S. G. On the sources and significance of interindustry differences in technological opportunities. Research Policy, v. 24, issue 2, p. 185-205, 1995.

KLECKA, W. R. Discriminant analysis. Beverly Hills: Sage, 1980.

KRAFFT, J.; QUATRARO, F.; SAVIOTTI, P. P. Knowledge characteristics and the dynamics of technological alliances in pharmaceuticals: empirical evidence from Europe, US and Japan. Journal of Evolutionary Economics, v. 24, issue 3, p. 587-622, $2014 \mathrm{a}$.

. The dynamics of knowledge intensive sectors' knowledge base: evidence from biotechnology and telecommunications. Industry and Innovation, v. 21, issue 3, p. 215-242, 2014 b.

LATTIN, J.; CARROLL, J.; GREEN, P. Analyzing multivariate data. Pacific Grove, CA: Thomson Learning, 2003.

LEIPONEN, A.; DREJER, I. What exactly are technological regimes? Intra-industry heterogeneity in the organization of innovation activities. Research Policy, 36, issue 8, p. 1221-1228, 2007.

MALERBA, F; ORSENIGO, L. Technological regimes and firm behavior. Industrial and Corporate Change, v. 2, issue 1, p. 45-71, 1993.

. Schumpeterian patterns of innovation. Cambridge Journal of Economics, v. 19, issue 1, p. 47-65, 1995.

. Technological regimes and sectoral patterns of innovative activities, Industrial and Corporate Change, v. 6, issue 1, p. 83-117, 1997.

MANLY, B. F. J. Multivariate statistical methods: a primer. 2. ed. London: Chapman \& Hall, 1994.

Mayumi, K. E.; Gobara, C.; Rossoni, L.; Cunha, S. K. Padrões de cooperação tecnológica entre setores na indústria brasileira: uma análise quantitativa dos dados da Pintec 2001-2003. Revista de Administração e Inovação, v. 5, n. 3, p. 126-140, 2008. 
MESA, A. F.; GAYO, I. G. Innovacion y tecnologia: uma contrastacion empirica de los regimenes tecnologicos Schumpeterianos. Cambio Tecnologico Y Competitividad, n. 781, p. 27-43, 1999.

MORRISON, D. G. On the interpretation of discriminant analysis. Journal of Marketing Research, v. VI, p. 156-163, 1969.

NELSON, R.; WINTER, S. An evolutionary theory of economic change. Cambridge, MA: Harvard Business School Press, 1982.

NELSON, R. National Innovation Systems: a comparative analysis. Oxford: Oxford University, 1993.

PAVITT, K. Sectoral patterns of technical change: towards a taxonomy and a theory. Research Policy, v. 13, issue 6, p. 343-373, 1984.

PATTEL, P.; PAVITT, K. National innovation system: why they are important, and how they might be measured and compared. Economics of innovation and New Technology, v. 3, issue 1, p. 77-95, 1994.

SCHUMPETER, J. A. The theory of economic development. Oxford: Oxford University Press, 1912.

Capitalism, socialism and democracy. New York: Harper, 1942.

SILVA, E. H. Taxonomia setorial com indicadores de esforço inovativo. Revista de Economia Contemporânea, v. 17, n. 1, 129-152, 2013.

SUTTON, J. Sunk costs and market structure. Cambridge, MA: MIT Press, 1991.

VAN DIJK, M. Technological regimes and industrial dynamics: the evidence from Dutch manufacturing. Industrial and Corporate Change, v. 9, issue 2, p. 173-194, 2000. Technological change and the dynamics of industries. Amsterdam: North-Holland, 2002.

WINTER S. G. Schumpeterian competition in alternative technological regimes, Journal of Economic Behaviour and Organization, v. 5, issue 3-4, p. 287-320, 1984.

ZUCOLOTO, G. F.; TONETO JR., R. Esforço tecnológico da indústria de transformação brasileira: uma comparação com países selecionados. Revista de Economia Contemporânea, v. 9, n. 2, p. 337-365, 2005. 


\section{Appendix I \\ Principal component analysis for SCHUMP variable}

TABLE 1

Summary statistics - indicators for regime classification

\begin{tabular}{l|c|c|c|c|c}
\hline \multicolumn{1}{c|}{ Variable } & Obs & Mean & Std. Dev. & Min & Max \\
\hline Stab & 69 & 0,225 & 0,143 & 0,016 & 0,775 \\
Entry & 69 & 0,278 & 0,077 & 0,091 & 0,435 \\
Conc & 69 & 0,337 & 0,250 & 0,062 & 1,000 \\
Schmp & 69 & 0,042 & 0,189 & 0,168 & 0,933 \\
\hline
\end{tabular}

Source: Elaborated by the the authors based on data released by IBGE

TABLE 2

Principal components - communalities (n. of obs.: 69)

\begin{tabular}{c|c|c|c}
\hline Components & Eigenvalue & Proportion of variance & $\begin{array}{c}\text { Cummulative } \\
\text { proportion of variance }\end{array}$ \\
\hline 1 & 1.597 & 0.533 & 0.533 \\
2 & 0.707 & 0.236 & 0.768 \\
3 & 0.695 & 0.232 & 1.000 \\
\hline
\end{tabular}

Source: Elaborated by the the authors based on data released by IBGE

TABLE 3

Principal components - factor loadings (n. of obs.: 69)

\begin{tabular}{c|c|c|c}
\hline Variable & Comp1 & Comp2 & Comp3 \\
\hline ENT & -0.576 & 0.683 & 0.450 \\
CONC & 0.575 & 0.729 & -0.371 \\
STAB & 0.581 & -0.045 & 0.813
\end{tabular}

Source: Elaborated by the the authors based on data released by IBGE 


\section{Appendix II}

\section{Descriptive statistics of Brazilian SM-I and SM-II sector}

\begin{tabular}{|l|ccc|c|c|c|}
\cline { 2 - 7 } \multicolumn{1}{c|}{} & \multicolumn{3}{c|}{ Schumpeter Mark I } & \multicolumn{3}{c|}{ Schumpeter Mark II } \\
\hline & Stability & Entry & Concentration & Stability & Entry & Concentration \\
\hline Sectors & 14 & 14 & 14 & 55 & 55 & 55 \\
Mean & 0,182 & 0,321 & 0,178 & 0,257 & 0,261 & 0,384 \\
Median & 0,178 & 0,316 & 0,174 & 0,254 & 0,262 & 0,296 \\
Std. Dev & 0,057 & 0,059 & 0,077 & 0,142 & 0,077 & 0,260 \\
Max & 0,212 & 0,488 & 0,293 & 0,775 & 0,425 & 1,000 \\
Min & 0,016 & 0,274 & 0,062 & 0,017 & 0,091 & 0,085 \\
\hline
\end{tabular}

Source: Elaborated by the the authors based on data released by Pintec.

\section{Appendix III}

\section{Perpetual inventory Method}

The stock of the capital variable, used as a component of the capital intensity variable, is built by using the perpetual inventory method. This method makes it possible to estimate the capital stock, starting from an initial depreciated capital stock and then summing the acquisitions (investments) in machinery and equipment and subtracting the losses from fixed assets. This method can be summarized by the following equation:

$$
K_{j, t+1}=\left(I_{j, t}-D_{j, t}\right)+(1-\delta) K_{j, t}
$$

where $\mathrm{K}_{\mathrm{jt+1}}$ and $\mathrm{K}_{\mathrm{jt}}$ is, respectively, the capital stock of sector $j$ in the $t+1$ and $t$ periods; $I_{j t}$ is the investment of sector $j$ in period $t ; \mathrm{D}_{\mathrm{j}, \mathrm{t}}$ is the deduction in the fixed assets, $\delta$ is the average rate of depreciation, which we assumed, based on studies of Alves and Silva (2008) and Ferreira \& Guillién (2004), equal to 9\%.

As shown above, it was necessary to define an initial stock of capital to enable us to estimate the remaining periods in the sample. The 1995 stock of capital was set as the initial point because that year was the last in which the IBGE disclosed an estimated stock of capital measured by the total fixed assets. Consequently, after 1995 , the capital stock data were obtained recursively by adding the net investments 
made in the current year (investments in machinery and equipment less the scrapping of fixed assets) to the previous year's deflated capital stock. The application of this method allowed us to estimate the stock of capital for the period from 1995 to 2005, enabling us to build the capital intensity variable.

\section{Appendix IV}

\section{Industrial sectors classified according to their technological regimes}

\begin{tabular}{|c|c|c|}
\hline CNAE & Sectors & SCHUMP \\
\hline \multicolumn{3}{|c|}{ Schumpeter Mark I } \\
\hline 152 & $\begin{array}{l}\text { Processing, preservation and production of canned fruits, vegetables and } \\
\text { other vegetables }\end{array}$ & $-0,113$ \\
\hline 154 & Dairy* & $-0,114$ \\
\hline 155 & Grind, starch products manufacturing and balanced diets for animals & $-0,123$ \\
\hline 158 & Manufacture of other food products* & $-0,047$ \\
\hline 176 & $\begin{array}{l}\text { Manufacture of artifacts from textile fabric - except apparel - textile and } \\
\text { other items }\end{array}$ & $-0,043$ \\
\hline 212 & Manufacture of paper, plain cardboard, cardboard and card & $-0,031$ \\
\hline 222 & Printing and related services for third & $-0,066$ \\
\hline 242 & Organic chemicals manufacturing * & $-0,018$ \\
\hline 245 & Manufacture of pharmaceutical products & $-0,16$ \\
\hline 246 & Manufacture of agricultural defensive & $-0,007$ \\
\hline 247 & $\begin{array}{l}\text { Manufacture of soaps, detergent, cleaning products and articles of } \\
\text { perfume* }\end{array}$ & $-0,042$ \\
\hline 248 & Manufacture of paints, varnish, enamels, lakes and related products & $-0,072$ \\
\hline 249 & Manufacture of chemicals and preparations miscellaneous & $-0,166$ \\
\hline 251 & Manufacture of rubber & $-0,04$ \\
\hline 264 & Manufacture of ceramic * & $-0,01$ \\
\hline 271 & Production of pig iron and ferroalloy* & $-0,056$ \\
\hline 275 & Foundry & $-0,118$ \\
\hline 282 & Fabrication of tanks, boilers and metal reservoirs & $-0,143$ \\
\hline 283 & Forging, stamping, powder metallurgy and metal processing services * & $-0,105$ \\
\hline 289 & Manufacture of miscellaneous metal & $-0,096$ \\
\hline 291 & Manufacture of engines, pumps, compressors and transmission equipment & $-0,103$ \\
\hline 292 & Manufacture of machinery and equipment for general use & $-0,147$ \\
\hline
\end{tabular}

(continua) 


\begin{tabular}{|c|c|c|}
\hline CNAE & Sectors & SCHUMP \\
\hline \multicolumn{3}{|c|}{ Schumpeter Mark I } \\
\hline 293 & $\begin{array}{l}\text { Manufacture of tractor and machinery and equipment for agriculture, and } \\
\text { poultry products procurement of animals * }\end{array}$ & $-0,128$ \\
\hline 296 & Manufacture of machinery and equipment other specific use & $-0,086$ \\
\hline 302 & $\begin{array}{l}\text { Manufacture of machinery and equipment for electronic systems data } \\
\text { processing }\end{array}$ & $-0,062$ \\
\hline 313 & Manufacture of wires, cables and electric leads isolated & $-0,08$ \\
\hline 315 & Manufacture of lamps and lighting equipment & $-0,092$ \\
\hline 316 & Manufacture of electrical equipment for vehicles - except batteries & $-0,036$ \\
\hline 321 & Manufacture of basic electronic material * & $-0,005$ \\
\hline 323 & $\begin{array}{l}\text { Manufacture of radio and television receivers and playback, recording or } \\
\text { amplification of sound and video * }\end{array}$ & $-0,095$ \\
\hline 331 & $\begin{array}{l}\text { Manufacturing equipment and tools for medical uses-hospital, and dental } \\
\text { laboratories and apparatus orthopedic }\end{array}$ & $-0,131$ \\
\hline 332 & $\begin{array}{l}\text { Manufacturing equipment and measuring instruments, and control test - } \\
\text { control equipment except industrial processes }\end{array}$ & $-0,109$ \\
\hline 333 & $\begin{array}{l}\text { Manufacture of machinery and equipment electronic systems industrial } \\
\text { automation and dedicated to control the production process }\end{array}$ & $-0,117$ \\
\hline 334 & $\begin{array}{l}\text { Manufacturing equipment, materials and optical instruments, } \\
\text { photographic and film }\end{array}$ & $-0,054$ \\
\hline 343 & Manufacture of cabins, carts and trailers & $-0,060$ \\
\hline 344 & Manufacture of parts and accessories for automotive vehicles & $-0,111$ \\
\hline
\end{tabular}

Source: Classificação Anual de Atividades Econômicas. 
